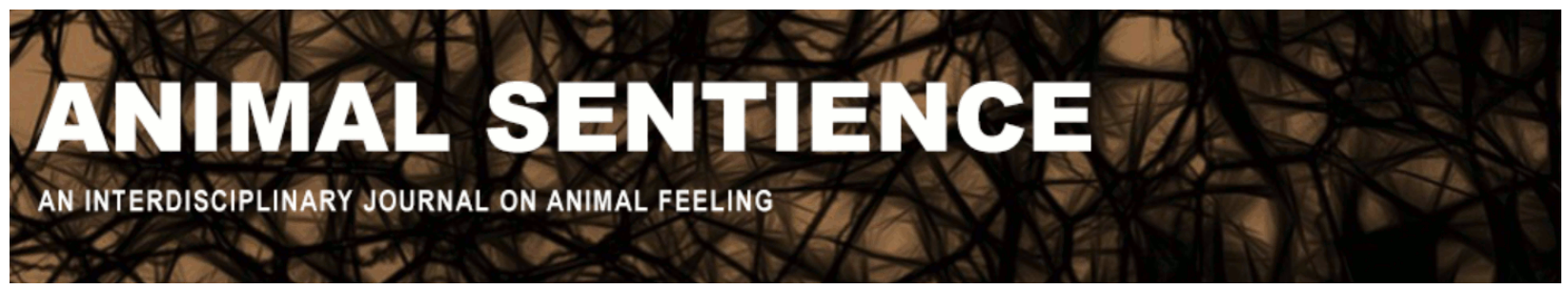

Duncan, Ian J.H. (2016) Is sentience only a nonessential component of animal welfare?. Animal Sentience 5(6)

DOI: $10.51291 / 2377-7478.1023$

Date of submission: 2015-08-10

Date of acceptance: 2015-12-13

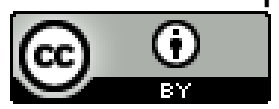

This article has appeared in the journal Animal

Sentience, a peer-reviewed journal on animal

cognition and feeling. It has been made open access,

free for all, by WellBeing International and deposited

in the WBI Studies Repository. For more information,

please contact

wbisr-info@wellbeingintl.org.

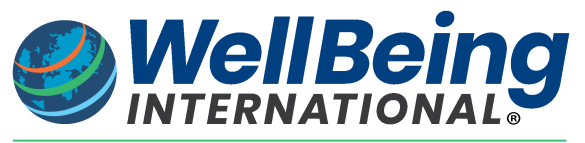

SOLUTIONS FOR PEOPLE, ANIMALS AND ENVIRONMENT 


\title{
Is sentience only a nonessential component of animal welfare?
}

Commentary on Broom on Animal Welfare

\author{
Ian J.H. Duncan \\ Department of Animal Biosciences \\ University of Guelph
}

\begin{abstract}
According to Broom (2014), animal welfare is a concept that can be applied to all animals, including single-celled organisms that are obviously not sentient. Such a stance makes it difficult to draw a connection between welfare and sentience, and that is the book's downfall. Some excellent points are made about sentience and there are very good discussions on animal welfare. However, unless sentience is considered the essential component of welfare, any attempt to link the two phenomena will be unsuccessful - and that, indeed, is the case with this book.
\end{abstract}

Ian Duncan iduncan@uoguelph.ca is Professor Emeritus and Emeritus Chair in Animal Welfare at the University of Guelph in Canada. He was one of the first to bring a scientific approach to solving welfare problems, developing methods of "asking" animals what they feel about the conditions in which they are kept and the procedures to which they are subjected. http://www.uoguelph.ca/abw/people/\#duncan

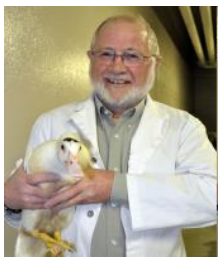

Right from the start, I had a problem trying to decide which audience Professor Broom was aiming at with his recently published book Sentience and Animal Welfare (2014). Is it the lay public? If so, it does not tell a very captivating story. Is it undergraduate students? Again, the theme is fractured and does not hang together very well. If it is intended for a more advanced audience, then it is simply too elementary. Good points are made throughout the text, but it neither tells a good story nor moves the science of animal welfare forward in any discernable way.

Broom's coverage of the history of understanding sentience in animals and of animal welfare science is somewhat inadequate. For example, in Chapter 1, he reaches back to the 1990s to describe the qualities that make up sentience. And yet William Youatt (1839) had described most of these qualities 150 years previously. Also in the 19th century, George John Romanes had taken up where Darwin's The Descent of Man (1871) and The Expression of the Emotions in Man and Animals (1872) had left off.

In his book Mental Evolution in Animals, George J. Romanes (1884) wrote that "Pleasures and Pains must have been evolved as the subjective accompaniment of processes which are respectively beneficial or injurious to the organism, and so evolved for the purpose or to the end that the organism should seek the one and shun the other." Later he stated, "Thus, then we see that the affixing of painful or disagreeable states of consciousness to deleterious changes of 
the organism, and the reverse states to reverse changes, has been a necessary function of the survival of the fittest." So by the 1880s, Romanes was saying almost exactly what animal welfare scientists are saying today. Broom would do better to try to explain why it took so long for feelings to be accepted as critical for welfare.

Duncan and Fraser (1997) describe three schools of thought on what animal welfare is all about:

(1) Welfare is to do with the subjective experience of animals, i.e., how much they experience pleasure and suffering. Into this school, amongst others, they placed Dawkins (1980, 1988, 1990), Duncan and Dawkins (1983), and Duncan (1987) and Fraser (1993).

(2) Welfare is to do with good biological functioning in the animal. Welfare will be reduced by disease, injury and malnutrition. Good welfare will be indicated by high levels of growth and reproduction, normal physiological functioning, and a high degree of biological fitness. Curtis (1987), Fraser and Broom (1990), and Broom and Johnson (1993) fall into this school.

(3) Welfare is to do with natural living. Welfare will be increased by keeping animals in "natural" environments that allow them to engage in "natural" behaviour. Into this school of thought were placed Webster et al. (1986) and Rollin (1992, 1993).

In two of Broom's textbooks published in the early 1990s, Farm Animal Behaviour and Welfare, (Fraser and Broom, 1990) and Stress and Animal Welfare (Broom and Johnson, 1993), little mention is made of the role of sentience. The approach to animal welfare outlined in both these books is most definitely based on whether the animal's biological systems are functioning normally. Broom is therefore rather late in aligning with the "Feelings School." Perhaps because of this lateness, he seems now to strive desperately to make up for lost time, but he does not succeed in marrying sentience to animal welfare very convincingly. Nevertheless, he is welcome to the fold, even if his commitment to sentience is not entirely wholehearted.

Chapter 2, dealing with ethics, morality and attitudes, was one of the weaker chapters in the book. Any first-year university text such as The Elements of Moral Philosophy by James Rachels (2003) gives a much clearer philosophical approach to various everyday problems including how we deal with animals. Broom covers humankind's obligations to animals reasonably well but dismisses Animal Rights out of hand. In my opinion, obligations and rights are simply opposite sides of the same coin. I have an obligation not to lie to you; you have a right not to be lied to by me. If we have an obligation not to cause injury to animals, do animals not have a right not to be injured by us? It is ironic that on page 15, where Rights are described and dismissed, there is a table with the caption Evidence that can be used to decide which animals should be protected, which could easily be reworded as Evidence that can be used to decide which animals have a right to be protected.

Also in Chapter 2, the notion of Freedom as applied to animals is described, and here I find myself much more in tune with Broom. I think the idea of "The Five Freedoms" was a useful 
stop-gap measure in the early days of animal welfare science, but one which we should have moved way beyond in 2015. Hunger and thirst, and pain and discomfort are all absolutely essential subjective states that have evolved to help the animal protect itself. There can never be complete freedom from those states. What we should be striving for is freedom from suffering - in other words, freedom from intense and long-term negative feelings.

My criticisms of Chapter 3 are similar to those of Chapter 1. It is interesting that reference is made to Ruth Harrison's (1964) book Animal Machines without pointing out that all of her criticisms of intensive animal husbandry systems were based on the feelings of the animals involved. She said quite explicitly that when treated in certain ways, these animals would be frightened or frustrated or in pain. Similarly, it was stated in the Brambell Report (Command Paper 2836, 1965), which was published in response to the huge public outcry following the publication of Animal Machines, that "Welfare is a wide term that embraces both the physical and mental well-being of the animal. Any attempt to evaluate welfare, therefore, must take into account the scientific evidence available concerning the feelings of animals that can be derived from their structure and functions and also from their behaviour" (emphasis is mine). The chapter describes a lot of research into animal stress and the scientists who were involved, but ignores the fact that both Harrison and the Brambell Committee were pointing to feelings as an important component of welfare in the early 1960 s.

Later in Chapter 3, Broom introduces the concept of "coping" and gives several references to previous papers of his that have described it. In my view, "coping" is a weasel word. It has a generally understood, non-scientific meaning that (in my opinion) does not translate into scientific terms. It has no explanatory value. In 25 years of teaching animal welfare science, I have not used the word or the "concept." I suspect that the only reason that the World Organization for Animal Health (OIE, 2011) refer to it is that they have heard Broom repeating it so often that they thought there must be a well-established concept involving coping.

Chapter 3 finishes with an unsuccessful attempt to link animal welfare with sentience. The statement is made, "Hence it is possible to consider the welfare of any animal." I disagree with this idea completely and concur with Kirkwood (2006) that welfare is a characteristic of only sentient animals. If "welfare" can be applied to single-celled animals, then why cannot it be applied to single-celled plants? Why not to plants in general? If used in such a loose way, the term loses all of its meaning and power.

Chapter 4 is an interesting account of animals' cognitive abilities, which I enjoyed reading. However, the relationship of these abilities to welfare is not fully explained. And in the words of Jeremy Bentham, "The question is not, Can they reason? nor, Can they talk? But, Can they suffer?" (Bentham, 1823).

Chapter 5 deals with feelings and emotions and is one of the stronger chapters in this book. The contents are fairly comprehensive, although frustration is not mentioned. This would also have been a good opportunity to mention malaise or feeling ill and contrasting that with being ill. Boredom, which is generally regarded as a negative emotional state, is also missing. However, the topics that are covered are covered well. 
The next two chapters deal with awareness and consciousness, and motivation and needs. I felt that these were good as far as they went, but they would benefit from some expansion.

Welfare Assessment is covered in Chapter 8, and Broom's leaning to the Biological Functioning school of thought is clearly demonstrated. He covers the physiological indicators of poor welfare very thoroughly. However, surely the crucial question is "Does it matter to the animal?" This seems to get tacked on as an afterthought. In my view, the question of whether it matters to the animal should be the primary one. The answer to this question can then be backed up and corroborated by physiological indicators. If it doesn't matter to the animal, then it is of no consequence to the animal's welfare.

Towards the end of this chapter there is a good discussion on the integration of welfare measures and a very fair and balanced review of Wemelsfelder's ideas. I am certain that this field will gain importance as we investigate it in more depth. I thought that the following section on risk and benefit analysis was also interesting. There can be little doubt that cattle with bovine spongiform encephalopathy are actually suffering from it (at least in the latter stages of the disease). However, it would have been nice to incorporate some anomalies. For example, does a very fast-growing and apparently thriving broiler chicken who succumbs in its fourth week of life to sudden death syndrome have good welfare or poor welfare?

Chapter 9 has a good discussion of sentience during development that compares altricial with precocial species. The work of David Mellor is well covered (e.g., Mellor et al., 2005), including the potential for suffering in fetal and newborn animals. I thought the suggestions as to when sentience might be considered as existing in a fetal animal were good, but perhaps they did not take sufficient account of the previous discussion about altricial and precocial species.

So Broom considers that an individual may be considered sentient after $50-70 \%$ of the development period up to birth or hatching. However, a marsupial that has $70 \%$ development before birth will be much less sentient than a lamb that has $70 \%$ development before birth. Similarly, a sparrow that has $70 \%$ development before hatching will be much less sentient than a domestic chick that has $70 \%$ development before hatching. Nevertheless, the conclusion is that, if procedures that require anaesthesia or analgesia in a newly born or newly hatched individual are carried out on a fetal individual that is suspected of being sentient, then that individual should be given anaesthetic or analgesic cover as well.

In Chapter 10, the question is raised about which animals should be protected. Broom states that many people consider that sentience is a criterion for deciding which animals should be legally protected by laws. (I would argue that this should be the only criterion). However, he goes on to restate that the concept of welfare can be applied to all animals. In my opinion, this devalues the term completely. It doesn't matter to a protozoan what happens to it. If it makes sense to talk about the welfare of a protozoan, then why not of a potato?

The final chapter of the book deals with sustainability (but the connection to sentience or animal welfare is unclear to me), welfare attitudes and education. The latter two topics are 
covered quite well. The description of welfare improvements to farm animals coming about as a result of consumer pressure is good. The section on the welfare of wild animals and pests is also dealt with in a balanced way. As a Canadian, I appreciated the discussion on the seal hunt, which Broom handles very fairly. The seal hunt is not the torture chamber that it is often portrayed as. However, neither is it humane, and Broom lays out the evidence very objectively.

There is a fairly long section on the effects of genetic modification (GM) on welfare. I would have liked to see more on the effects of conventional breeding methods on welfare, which are touched on only briefly. In many ways, conventional breeding practices are more insidious; changes occur gradually and by the time a welfare problem is recognized, the original breeding stock have disappeared, and it is difficult to correct the problem. On the other hand, effects due to GM can be recognized early in the breeding program. If these are deleterious to welfare they can be stopped immediately (assuming that there is a will to stop them).

This final chapter ends with a brief description of laws and codes designed to protect welfare, and a short section on teaching animal welfare.

\section{References}

Bentham, J., 1823. An Introduction to the Principles of Morals and Legislation. Clarendon Press, Oxford, UK.

Broom, D.M., 2014. Sentience and Animal Welfare. CABI Publishing, Wallingford, UK.

Broom, D.M. and Johnson, K.G., 1993. Stress and Animal Welfare. Chapman and Hall, London, UK.

Command Paper 2836, 1965. Report of the Technical Committee to Enquire into the Welfare of Animals kept under Intensive Livestock Husbandry Conditions. HMSO, London.

Darwin, C., 1871. The Descent of Man, and Selection in Relation to Sex. John Murray, London, UK.

Darwin, C., 1872. The Expression of the Emotions in Man and Animals. John Murray, London, UK.

Dawkins, M.S., 1980. Animal Suffering: The Science of Animal Welfare. Chapman and Hall, London, UK.

Dawkins, M.S., 1988. Behavioural deprivation: a central problem in animal welfare. Appl. Anim. Behav. Sci., 20: 209-225.

Dawkins, M.S., 1990. From an animal's point of view: motivation, fitness, and animal welfare. Behav. Brain Sci., 13: 1-9 and 54-61. 
Duncan, I.J.H., 1987. The welfare of farm animals: an ethological approach. Sci. Prog. Oxford, 71: 317-326.

Duncan, I.J.H. and Dawkins, M.S., 1983. The problem of assessing 'well-being' and 'suffering' in farm animals. In: Smidt, D. (Ed.), Indicators Relevant to Farm Animal Welfare. Martinus Nijhoff, The Hague, The Netherlands, pp. 13-24.

Duncan, I.J.H. and Fraser, D., 1997. Understanding animal welfare. In: Applby, M.C. and Hughes, B.O. (Eds.), Animal Welfare. CABI Publishing, Wallingford, UK, pp. 19-31.

Fraser, A.F. and Broom, D.M., 1990. Farm Animal Behaviour and Welfare, 3rd ed. Baillière Tindall, London, UK.

Fraser, D., 1993. Assessing animal well-being: Common sense, uncommon science. In: Food Animal Well-Being. Purdue University Office of Agricultural Research Programs, West Lafayette, IN, pp. 37-54.

Harrison, R., 1964. Animal Machines. Vincent Stuart, London, UK.

Mellor, D.J., Diesch, T.J., Gunn, A.J. and Bennet, L., 2005. The importance of 'awareness' for understanding fetal pain. Brain Res. Revs., 49: 455-471.

OIE, 2011. Terrestial Animal Health Code. OIE, Paris.

Rachels, J., 2003. The Elements of Moral Philosophy, 4th ed. McGraw-Hill, Boston, MA.

Rollin, B.E., 1992. Animal Rights and Human Morality. Revised edition. Prometheus Books, Buffalo, NY.

Rollin, B.E., 1993. Animal welfare, science and value. J. Agri. Environ. Ethics, 6 (Suppl. 2), 44-50.

Romanes, G.J., 1884. (reprinted 1969). Mental Evolution in Animals. AMS Press, New York, NY.

Webster, J., Saville, C. and Welchman, D., 1986. Improved Husbandry Systems for Veal Calves. Farm Animal Care Trust, London, UK.

Youatt, W., 1839. The Obligation and Extent of Humanity to Brutes, Principally Considered with Reference to the Domesticated Animals. Republished in 2004. Edited, introduced and annotated by R. Preece. Edwin Mellen Press, Lewiston, NY. 